\title{
Investigating Delay in Treatment for First Symptoms of Psychosis Based on Demographic and Social Factors in Patients Referred to Farabi Hospital of Kermanshah (2015)
}

\author{
Masoumeh Heidarian (iD ${ }^{1}$, Hassan Ahadi ${ }^{2,{ }^{*}}$, Jalal Shakeri ${ }^{3}$ and Amir Hossein Hashemian ${ }^{4}$ \\ ${ }^{1}$ Department of Health Psychology, Ph.D. Student, Karaj Branch, Islamic Azad University, Karaj, Iran \\ ${ }^{2}$ Department of Health Psychology, Karaj Branch, Islamic Azad University, Karaj, Iran \\ ${ }^{3}$ Department of Psychiatry, Behavioral Sciences Research Center, Kermanshah University of Medical Sciences, Kermanshah, Iran \\ ${ }^{4}$ Department of Biostatistics, Faculty of Health, Kermanshah University of Medical Sciences, Kermanshah, Iran \\ "Corresponding author: Professor of Health Psychology Department, Karaj Branch, Islamic Azad University, Karaj, Iran. Email: drhahadi5@gmail.com
}

Received 2018 November 17; Accepted 2018 November 18.

\begin{abstract}
Background: Delay in treating the symptoms of psychosis, both in terms of personal and family problems and in terms of economic and social consequences, is of particular importance. The purpose of this study is to investigate demographic and social factors associated with delay in treatment for first symptoms of psychosis in order to better prepare the ground for its prevention.

Methods: This is a descriptive cross-sectional study performed using a sequential sampling method on all patients who experienced the first psychosis attack. Then, data are extracted from a clinical interview based on clinical checklist approved by specialists. Using SPSS software (V.25) descriptive statistics including frequency, mean and standard deviation were obtained, and also Kruskal-Wallis and Mann-Whitney tests were performed.

Results: The obtained results showed that mean delay in treatment for first symptoms of psychosis was $48.5 \pm 65.6$ weeks. There was a significant relationship between gender $(P=0.0353)$, age $(P=0.0198)$, father's occupation $(P=0.0198)$, history of referral to the first therapist $(\mathrm{P}=0.0059)$, and source of referral $(\mathrm{P}=0.0497)$, on one hand, and delay in treatment for first symptoms of psychosis. Conclusions: The results of this study indicated that, with better understanding of demographic and social factors, besides educating families and doctors, it may be possible to help reducing the overall time of referral to a psychiatric services provider and thereby contribute to First treatment of the patients.
\end{abstract}

Keywords: Delay in Treatment, First Symptoms of Psychosis, Demographic Factors, Social Factors

\section{Background}

Psychosis is a psychiatric disorder in which thoughts, emotional responses, ability to recognize reality, speech ability, and communication with others are completely degraded so that one's ability to connect to reality and deal with it is disturbed (1). In the fifth diagnostic and statistical manual of mental disorder, psychosis includes a range of definitions. The narrowest definition is existence of prominent delusions and hallucinations which is not considered as an illness by the patient. In a broad definition, it refers to prominent illusions that a person accepts as illusory experiences. This definition confirms gradual nature of insight in various diseases and individuals. A broader definition of psychosis includes other symptoms, such as disorganized thinking process or catatonic and disorganized behavior. All in all, the most general definition of psychosis is loss of ego boundaries and a significantly impaired experience of reality (2). The first episode psychosis (FEP), in $80 \%$ of cases, occurs between ages 16 and 20, which is a very critical period (3). Demographic and social factors are among factors influencing the outcome and duration of untreated psychosis (DUP). As defined in literature, DUP is the time interval between onset of psychotic symptoms and first appropriate treatment (4). Khodaeifar and Mottaghipour (5) surveyed demographic variables of the illness and treatment of first- episode psychosis in patients admitted to Taleghani Hospital, Tehran (Iran) and observed significant difference between demographic variables of Iranian and foreign patients in term of FEP treatment. That is, Iranian patients used more classical drugs that had positive effects on their symptoms while patients of other countries used more new (atypical) drugs with non-pharmacological treatments. In another research carried out by Sharifi et al. (6) to determine duration of untreated psychosis and 
pathways to care in patients with first-episode psychosis admitted to Roozbeh Hospital, Iran. Findings of this study showed that delay in treatment was not correlated with gender, marital status, level of education of the patient, roommates, number of roommates, and the place of first referral of the patient, but correlated with age, place of residence, and patient's occupation. In the study of Apeldoorn et al. (7), factors such as immigration status, age at onset of mental disorder and gender were substantially associated with delay in treatment. Also, in a research by Lihong et al. (8), duration of untreated psychosis in a rural/suburban region of Japan, long delay was associated with lower ages at onset of psychosis. In a research by Wunderink et al. (9), mean and median of delay in the treatment of psychotic symptoms were about 46 and 31 weeks, respectively, and long delay in treatment was in positive relationship with unemployment and having a male gender while short delay in treatment was associated with being employed and living with parents.

Psychiatric symptoms under the threshold of diagnosis do not necessarily lead to psychotic disorders and it depends on other factors such as biological vulnerability of an individual, childbirth complications, use of cannabis in adolescence, environmental factors affecting the illness such as poverty and low education, and protecting factors such as individual flexibility and family support. Among various psychiatric disorders, either in terms of personal and family problems or in terms of economic and social consequences, psychiatric disorders are very important (10).

Studies have shown that patients with the first stage of psychosis, before referring to a psychiatrist or psychologist, have had psychotic symptoms for a long time (11).

Besides, delay in onset of treatment is associated with increased problems such as severe behavioral disorders, family problems, and deadly behaviors. Increased risk of life-threatening situations as a result of aggression with suicidal behaviors and drug use for self-treatment may make the illness more sophisticated. Therefore, diagnosis of psychosis in its early stage is essential and attention to the patient, when vulnerability to first stage of psychosis appears, is of prime significance. It is hoped that appropriate interventions during this period can prevent irreversible social, neurological, and biological changes (12).

Harrigan et al. (13) conducted a research to see whether treatment delay in first-episode psychosis really matters? They found that long delay, more than short delay, results in gradual loss of individual's social function yet good outcome was variably associated with good pre-morbid adjustment. Delay in the treatment of psychotic symptoms is associated with increased time for recovery and response to treatment, reduced rate of recovery, and a greater in- cidence of psychosis (14). This study aims to identify and determine the relationship between demographic and social variables with duration of delay in treatment of psychotic symptoms. Given that variables affecting duration of delay in treatment of psychotic symptoms have not yet been fully identified and their communication complexities are not fully explained, more precise analysis of these factor may help educating families, doctors and psychologists share to reduce the overall referral time of the patients to psychiatric services providers, and thereby help them to be treated more quickly because nowadays special treatments are available for patients diagnosed with psychiatric disorders. On the other hand, living quality of patients and their families is also an important axiom of the treatment process. According to the results of previous studies on the effect of early interventions on living quality of psychiatric patients and their overall life outcomes (15), it seems necessary to conduct further studies on this issue in psychiatric centers or psychiatric departments of public hospitals of the country so as to find out, during a one-year period, how does delay in first-episode psychosis was influenced by demographic and social characteristics of patients referred to Farabi Psychiatric Hospital?

\section{Methods}

This is a descriptive cross-sectional study performed on all patients who experienced the first psychosis attack during March 21 (2015) to March 19 (2016) and referred to Farabi Psychiatric Center of Kermanshah. A total of 94 patients who had inclusion criteria and were willing to participate in the study were selected. Sample inclusion criteria were: Being diagnosed with psychosis by a psychiatrist based on five symptoms based on DSM-5 and ICD-10 criteria (hallucinations, delusions, disorganized behavior, negative symptoms, and disorganized speech), being admitted to Farabi Psychiatric Center, providing a written consent by the patient or his/her guardian to enter the study, having experience first psychosis attack, and being in the age range of 15 to 65 years old. Also, the patients were assured that participation in research is volunteering and their information will remain confidential.

Here, delay in treatment refers to interval between the onset of the first symptoms of psychosis and the first psychiatric attack, after which the person was referred and admitted to the Farabi Psychiatric Hospital of Kermanshah. The current research data was collected with a clinical interview based on a researcher-made checklist of demographic and social data approved by 20 experts in this field who were faculty members of Sanandaj and Kermanshah Universities of Medical Sciences. Using SPSS software (V.25) descriptive statistics including frequency, rate, mean and 
Table 1. Distribution of Delay in Treatment of Patients with Psychotic Symptoms Referred to Farabi Hospital of Kermanshah in 2015

\begin{tabular}{lc}
\hline Delay in Treatment of Patients, mo/y & No. $(\%)$ \\
\hline$<\mathbf{1}, \mathbf{m o}$ & $25(26.6)$ \\
\hline $\mathbf{1}$-3, mo & $18(19.1)$ \\
\hline $\mathbf{4}$ - $\mathbf{6}, \mathbf{m o}$ & $10(10.6)$ \\
\hline $\mathbf{7}-\mathbf{1 2}, \mathbf{m o}$ & $18(19.1)$ \\
\hline $\mathbf{1}-\mathbf{2}, \mathbf{y}$ & $11(11.7)$ \\
\hline $\mathbf{2}, \mathbf{y}$ & $12(12.8)$ \\
\hline Total & $94(100.0)$ \\
\hline
\end{tabular}

standard deviation were obtained, and also Kruskal-Wallis and Mann-Whitney tests were performed.

\section{Results}

$26.6 \%$ of the patients had less than one month delay in treatment. During the first 6 month, most of the subjects (56.3\%) referred with delay for treatment. Mean of delay in treatment for psychotic symptoms was $48.5 \pm 65.6$ weeks (Table 1 ).

Of the total subjects, $54.3 \%$ were male and $45.7 \%$ were married. The age range of $58.5 \%$ of them was 30 to 50 years. $42.6 \%$ of the patients were second or third child in the family and $36.2 \%$ of the subjects were householder. Education level of $61.7 \%$ of the subjects was below diploma. Income level of $83 \%$ of them was below one million Tomans. For the first treatment, $42.6 \%$ of them referred to a general practitioner and $20.2 \%$ of them referred to traditional therapist. $77.7 \%$ of them were referred for treatment by their families. Of all female subjects, 34.9\% referred for treatment in less than one month. Among male subjects, $19.6 \%$ referred for treatment of psychiatric symptoms in less than one month. Delay in treatment was from less than 1 week to 261 weeks in men and from less than 1 week to 233 weeks in women. In terms of age, less than one month delay in treatment was most witnessed among the age range of 15 - 24; i.e. patients aged 15 to 24 years had less delay in treatment of psychotic symptoms. But most delayed treatment was observed in patients aged 35 - 44 years. In terms of birth order, most of the patients (33\%) were the first child. Patients who were the first and fifth child in their family referred for treatment with less than one month delay (Tables 2 and 3).

There was a significant relationship between delay in treatment for symptoms of psychosis and gender. Also, there was a significant relationship between delay in treatment for symptoms of psychosis and age of the patients ( $P$

\begin{tabular}{|c|c|c|c|}
\hline Variables & No. (\%) & Duration of Delay ${ }^{a}$ & P Value \\
\hline Gender $^{b}$ & & & 0.0353 \\
\hline Female & $43(45.7)$ & $36.04 \pm 55.97$ & \\
\hline Male & $51(54.3)$ & $59.04 \pm 71.57$ & \\
\hline Age, $y^{c}$ & & & 0.0198 \\
\hline$<30$ & 30 (31.9) & $33.72 \pm 57.51$ & \\
\hline $30-50$ & $55(58.5)$ & $62.27 \pm 71.32$ & \\
\hline$>50$ & $9(9.6)$ & $13.73 \pm 13.97$ & \\
\hline Birth order $^{c}$ & & & 0.2988 \\
\hline 1 st & $31(33)$ & $48.35 \pm 75.329$ & \\
\hline 2nd and 3rd & $40(42.6)$ & $59.94 \pm 69.80$ & \\
\hline 4th and 5th & $18(19.1)$ & $31.98 \pm 37.24$ & \\
\hline 5th and above & $5(5.3)$ & $17.57 \pm 17.90$ & \\
\hline
\end{tabular}

${ }^{\text {a }}$ Values are expressed as mean $\pm \mathrm{SD}$.

b Mann-Whitney.

c Kruskal-Wallis.

$=0.0198)$. But, no significant relationship was found between delay in treatment for symptoms of psychosis and birth order of the patients $(P=0.2988)$ (Table 2$)$.

In terms of marital status, whether in single, married, or divorced subjects, delay in treatment for symptoms of psychosis was more than one month in most cases. More than $30 \%$ of single patients referred in less than one month delay for treatment. In terms of level of education, 30.8\% of those who had a diploma had less than a month delay for treatment indicating that with an increase in the level of education people may refer for treatment with less delay. In terms of employment status, more than $90 \%$ of unemployed patients referred for treatment with more than one month delay. In terms of father's occupation, all patients whose father was unemployed referred for treatment with more than one month delay. In terms of patients' record of referral for treatment, $42.6 \%$ of them had been referred to a general practitioner among whom $32.5 \%$ had less than one month delay. $37.2 \%$ of the patients referred to the psychiatrist, psychologist, counselor and other specialists for treatment, 28. $1 \%$ of those with a delayed treatment were referred to less than a month. $25.5 \%$ of the patients were referred for treatment by their siblings among whom $30.8 \%$ had less than one month delay. But $8.5 \%$ of the patients were referred to by police force. $87.5 \%$ had more than one month delay. There was a significant relationship between duration of delay in treatment for psychotic symptoms, on 
Table 3. The Effect of Social Factors on Frequency Distribution and Mean Duration of Delay in Treatment of Patients with Psychotic Symptoms Referred to Farabi Hospital of Kermanshah in 2015

\begin{tabular}{|c|c|c|c|}
\hline Variable & No. (\%) & Duration of Delay ${ }^{a}$ & P Value \\
\hline Marital status $^{\mathbf{b}}$ & & & 0.7820 \\
\hline Single & $43(45.7)$ & $53.65 \pm 73.00$ & \\
\hline Married & $43(45.7)$ & $39.23 \pm 54.719$ & \\
\hline Divorced & $8(8.5)$ & $70.75 \pm 77.12$ & \\
\hline Education $^{b}$ & & & 0.7538 \\
\hline Illiterate & $10(10.6)$ & $38.74 \pm 43.24$ & \\
\hline Below diploma & $48(51.1)$ & $53.27 \pm 69.53$ & \\
\hline Diploma & $26(27.7)$ & $53.25 \pm 74.42$ & \\
\hline Academic degree & $10(10.6)$ & $23.10 \pm 30.60$ & \\
\hline Patient's occupation ${ }^{b}$ & & & 0.1408 \\
\hline Unemployed & $11(11.7)$ & $103.21 \pm 103.07$ & \\
\hline House holder & $34(36.2)$ & $36.64 \pm 51.07$ & \\
\hline Public status & $4(4.2)$ & $34.11 \pm 47.21$ & \\
\hline Self-employed & $20(21.3)$ & $50.11 \pm 54.59$ & \\
\hline Other & $25(26.6)$ & $41.61 \pm 66.03$ & \\
\hline Father's occupation ${ }^{b}$ & & & 0.0198 \\
\hline Unemployed & $2(2.1)$ & $20.00 \pm 10.10$ & \\
\hline Public status & $7(7.4)$ & $61.78 \pm 74.65$ & \\
\hline Self-employed & $42(44.7)$ & $72.69 \pm 77.08$ & \\
\hline Military & $4(4.3)$ & $94.57 \pm 103.86$ & \\
\hline Other & $39(41.5)$ & $16.82 \pm 20.15$ & \\
\hline Income level $^{c}$ & & & 0.2533 \\
\hline Less than one million Tomans & $83(88.3)$ & $52.08 \pm 68.27$ & \\
\hline More than one million Tomans & $11(11.7)$ & $21.56 \pm 29.64$ & \\
\hline History of referral to the first therapist ${ }^{b}$ & & & 0.0059 \\
\hline General practitioner & $40(42.6)$ & $42.27 \pm 60.56$ & \\
\hline Psychiatrist, psychologist, advisor, and other specialists & $35(37.2)$ & $26.03 \pm 34.98$ & \\
\hline Traditional therapist & $19(20.2)$ & $103.06 \pm 88.06$ & \\
\hline Referral source $^{b}$ & & & 0.0497 \\
\hline Self-family & $73(77.7)$ & $45.91 \pm 63.91$ & \\
\hline Police force & $8(8.5)$ & $103.13 \pm 89.34$ & \\
\hline Roommate & $13(13.9)$ & $29.53 \pm 41.81$ & \\
\hline
\end{tabular}

${ }^{\text {a }}$ Values are expressed as mean $\pm \mathrm{SD}$.

${ }^{\mathrm{b}}$ Kruskal-Wallis.

${ }^{c}$ Mann-Whitney. 
one hand, and father's occupation $(\mathrm{P}=0.0198)$, history of referral to a therapist $(\mathrm{P}=0.0059)$, and referring source $(\mathrm{P}$ $=0.0497)$, on the other hand. There was no statistically significant relationship between marital status $(\mathrm{P}=0.7820)$, education ( $\mathrm{P}=0.7538)$, and patient's occupational status, $(\mathrm{P}$ $=0.1408$ ) with the duration of delay in treatment for psychotic symptoms. Also, there was no significant relationship with income level $(\mathrm{P}=0.2533)$ (Table 3$)$.

\section{Discussion}

According to findings of the current research, mean delay in treatment of the first symptoms of psychosis was $48.5 \pm 65.6$ which is consistent with findings of Large et al. (11) in a research on average duration of delay in treatment of symptoms of psychosis in low-and middle-income countries which were 125 and 63 weeks, respectively. That is, considering our per capita income, delay in treating first symptoms of psychosis are aligned with middle income countries. Wunderink et al. (9) found that long delay in treatment was directly associated with increased time to respond to treatment. It means that, the longer the time has passed since the onset of symptoms of psychosis, the more is the need for psychiatric therapies and the longer it takes for the patient to be treated. Pek et al. (16) and Barnes et al. (12) also revealed that short delay in treatment for symptoms of psychosis, in case it is less than one year, can be regarded as a good sign, especially if the patient is diagnosed with schizophrenia. These patients showed less recurrence and higher overall performance than patients who delayed for more than a year. In other words, when psychotic patients diagnosed with schizophrenia refer for appropriate treatment in less than a year, they are more probably show better performance and recovery without returning of psychotic symptoms than those who referred with more than one year delay. As regards, it is possible to reduce delay in the treatment of psychotic symptoms by informing people and families about the symptoms of psychosis and identifying mental health centers. This leads to decrease in duration of treatment, absence of loss of function, no recurrence of the disease, and non-chronic psychiatric disorder in patients.

There was a significant relationship between duration of delay in treatment for first symptoms of psychosis and gender which was consistent with findings of Apeldoorn et al. (7), Malla et al. (14), Sharifi et al. (6), and Wunderink et al. (9). To put it in other words, in this study, women referred for treatment with shorter delay than men. In this regard, it can be argued that women with shorter delay in treatment of symptoms of psychosis are more likely to show higher rate of recovery and treatment. Also, there was a significant relationship between duration of delay in treatment for first symptoms of psychosis and age of the patients which was in line with findings of Apeldoorn et al. (7), Malla et al. (14), Sharifi et al. (6), and Large et al. (4). According to Large et al. (4), long delay in treatment of symptoms of psychosis was correlated with lower age at onset of this disorder since most patients were less than 45 years old and more than half of them were below 35 years old. So, we are dealing with a young group of patients whose lives are severely affected by the outcome of this disorder. Thus, every effort should be made for early diagnosis of this illness and its appropriate treatment so as to prevent it from being chronic and reduce the burden of psychiatric disorders in the life of individuals and their family, and eventually the community (12). In addition, there was a significant correlation between father's occupation and duration of delay in treatment of symptoms of psychosis; i.e. those patients whose fathers were military man showed shorter delay for treatment than those patients whose fathers were self-employed. None of the previous studies reported a significant relationship between delay in treatment and father's occupation. Thus, in this regard, previous studies were not consistent with the results of the current research. It may be argued that military fathers discipline and low education level of self-employed fathers can be effective it obtaining these significant outcomes. The current research showed a significant correlation between history of referring to the first therapist and duration of delay in treatment of symptoms of psychosis which was consistent with findings of Amini (17) and Sharifi et al. (6) but inconsistent with the studies of Wunderink et al. (9), Gee et al. (10), Barnes et al. (12), Malla et al. (14), and Harrigan et al. (13). An important finding of this research is remarkable number of patients who referred to traditional therapists. According to surveys conducted in European countries, health centers are the first point of contact for most people with psychotic symptoms and contact with religious centers or traditional therapists is not common (18) so most patients referred to doctors and treatment centers to begin their treatment. In the same vein as the current study, Sharifi et al. (6) reported that more one third of the patients had referred to a traditional therapist throughout their illness. Nevertheless, it seems that traditional therapists have owned a significant part of patients' referrals, even those severe illnesses such as psychotic disorders. In this study, referral to general practitioner was more than a referral to psychiatrist and other mental health practitioners and traditional therapists. In previous studies, general practitioners were also considered as an important point of referral for first-time patients and their presence on this way reduced police involvement or forced admission (17). Besides, those patients who were more in touch with general practitioner showed shorter delay in treatment of psy- 
chotic symptoms. In this study, referring source had a significant correlation with delay in treatment of psychotic symptoms which was observed in most studies in this area, in particular, Sharifi et al. (6), Apeldoorn et al. (7), Lihong et al. (8), Gee et al (10), Casey et al. (15), Pek et al (16), and Chen et al. (19). Those who had been referred to treatment by their parents, siblings, or spouse had shorter delay in treatment than those who had been referred to by police force or their roommates. This indicates significant contribution of the family, especially spouses and parents, in supporting these patients and their impact on reducing delay in treatment of psychotic symptoms. Malla et al. (14) witnessed that those with good family relationships had shorter delay in treatment than others. Pek et al. (16) reported that patients who had been referred to treatment by police force had longer delay in treatment. Norman et al. (20) found that social support can affect delay in treatment of psychotic symptoms and is a primary determinant of treatment outcome. Long periods of delay in treatment of psychotic symptoms can be a reflection of poor social support and have early effects on treatment outcomes. They also suggested that attempts to reduce the interval between onset of symptoms and onset of treatment should include various factors, such as methods of referring patients to treatment centers and educating patients about treatment methods. Studies on how to refer patients for treatment showed that most patients are reluctant to be admitted to hospital due to impaired judgment and vision, so they are forced to be admitted.

In this study, there was no significant relationship between birth order, marital status, education, occupational status of patient, and income, on one hand, and delay in treatment of psychotic symptoms, on the other hand. As other researches, there were some limitations in this study, among which are the results of self-report realization and not use of detailed records. This study was also conducted among those who were admitted to Farabi Hospital of Kermanshah so it cannot be generalized to other samples. Given the importance of this study, future researchers are recommended, if possible, carry out a study on a larger sample size over a course of 5 to 10 years, to investigate the correlation between rate of recovery, recurrence and chronicity of the disease, and the type of diagnosed psychiatric disorders with the delay in treatment of psychotic symptoms.

\subsection{Conclusion}

According to results of this study and other similar studies, demographic and social factors associated with delay in treatment of first symptoms of psychosis are introduced as important factors affecting mental health promotion and absolute improvement of individuals. Identifica- tion of these factors will be the key to designing and implementing interventions based on healthcare provision. These interventions, along with proper planning, will improve the quality of lives of patients and their families. Thus, with better understanding of these factors, it may be possible to help reducing the overall time of referral to a psychiatric services provider and thereby contribute to faster treatment of the patients by educating families, doctors, and psychologists.

\section{Acknowledgments}

This article is adapted from a doctoral thesis. The researchers would like to thank and appreciate all patients without whom this research was not possible, Research Deputy of Kermanshah University of Medical Sciences for their supports, and personnel of Farabi Psychiatric Hospital of Kermanshah for their cooperation.

\section{References}

1. Kaplan H, Sadock B, Sadock V. [Comperhensive text of psychiatry.]. 10th ed. Tehran: Arjmand Publications; 2013. p. 817-20. Persian.

2. American Psychiatric Association. [Diagnostic and statistical manual of mental disorders.].5th ed. Arjmand Publication; 2013. p.129-63. Rezaee F, Fakhraee A, Niloofari A, translators. Persian.

3. Sayers J. The world health report 2001-mental health: New understanding, new hope. Bulletin of the World Health Organization. Geneva: WHO;2001.

4. Large M, Nielssen O, Slade T, Harris A. Measurement and reporting of the duration of untreated psychosis. Early Interv Psychiatry. 2008;2(4):201-11. doi: 10.1111/j.1751-7893.2008.00080.x. [PubMed: 21352155].

5. Khodaeifar F, Mottaghipour Y. [Survey of demographic, illness and treatment variables of first-episode psychosis in patients admitted to Taleghani Hospital, Tehran, Iran]. Res Med. 2008;32(4):309-14. Persian.

6. Sharifi V, Kermani-Ranjbar T, Amini H, Alaghband-rad J, Salesian $\mathrm{N}$, Seddigh A. Duration of untreated psychosis and pathways to care in patients with first-episode psychosis in Iran. Early Interv Psychiatry. 2009;3(2):131-6. doi: 10.1111/j.1751-7893.2009.00119.x. [PubMed: 21352186].

7. Apeldoorn SY, Sterk B, van den Heuvel ER, Schoevers RA, Islam MA, Genetic R, et al. Factors contributing to the duration of untreated psychosis. Schizophr Res. 2014;158(1-3):76-81. doi: 10.1016/j.schres.2014.07.002. [PubMed: 25043913].

8. Lihong Q, Shimodera S, Fujita H, Morokuma I, Nishida A, Kamimura $\mathrm{N}$, et al. Duration of untreated psychosis in a rural/suburban region of Japan. Early Interv Psychiatry. 2012;6(3):239-46. doi: 10.1111/j.17517893.2011.00325.x. [PubMed: 22221408].

9. Wunderink A, Nienhuis FJ, Sytema S, Wiersma D. Treatment delay and response rate in first episode psychosis. Acta Psychiatr Scand. 2006;113(4):332-9. doi: 10.1111/j.1600-0447.2005.00685.x. [PubMed: 16638078].

10. Gee B, Hodgekins J, Fowler D, Marshall M, Everard L, Lester H, et al. The course of negative symptom in first episode psychosis and the relationship with social recovery. Schizophr Res. 2016;174(1-3):165-71. doi: 10.1016/j.schres.2016.04.017. [PubMed: 27131912].

11. Large M, Farooq S, Nielssen O, Slade T. Relationship between gross domestic product and duration of untreated psychosis in lowand middle-income countries. Br J Psychiatry. 2008;193(4):272-8. doi: 10.1192/bjp.bp.107.041863. [PubMed: 18827287]. 
12. Barnes TR, Leeson VC, Mutsatsa SH, Watt HC, Hutton SB, Joyce EM. Duration of untreated psychosis and social function: 1-year follow-up study of first-episode schizophrenia. BrJPsychiatry. 2008;193(3):203-9. doi: 10.1192/bjp.bp.108.049718. [PubMed: 18757977]. [PubMed Central: PMC2576506].

13. Harrigan SM, McGorry PD, Krstev H. Does treatment delay in firstepisode psychosis really matter? Psychol Med. 2003;33(1):97-110. doi: 10.1017/S003329170200675X. [PubMed:12537041].

14. Malla AK, Norman RM, Joober R. First-episode psychosis, early intervention, and outcome: What have we learned? Can J Psychiatry. 2005;50(14):881-91. doi: 10.1177/070674370505001402. [PubMed: 16494257].

15. Casey D, Brown L, Gajwani R, Islam Z, Jasani R, Parsons H, et al. Predictors of engagement in first-episode psychosis. Schizophr Res. 2016;175(1-3):204-8. doi: 10.1016/j.schres.2016.04.030. [PubMed: 27132495].

16. Pek E, Mythily S, Chong SA. Clinical and social correlates of duration of untreated psychosis in first-episode psychosis patients. Ann Acad Med Singapore. 2006;35(1):24-6. [PubMed: 16470270].

17. Amini H. First-episode psychosis: An overview of research in Iran. Iran J Psychiatr Behav Sci. 2011;5(1):6-16

18. Cougnard A, Kalmi E, Desage A, Misdrahi D, Abalan F, Brun-Rousseau $\mathrm{H}$, et al. Pathways to care of first-admitted subjects with psychosis in South-Western France. Psychol Med. 2004;34(2):267-76. doi: 10.1017/S003329170300120X. [PubMed: 14982132].

19. Chen EY, Dunn EL, Miao MY, Yeung WS, Wong CK, Chan WF, et al. The impact of family experience on the duration of untreated psychosis (DUP) in Hong Kong. Soc Psychiatry Psychiatr Epidemiol. 2005;40(5):350-6. doi: 10.1007/s00127-005-0908-z. [PubMed: 15902405].

20. Norman RM, Malla AK, Verdi MB, Hassall LD, Fazekas C. Understanding delay in treatment for first-episode psychosis. Psychol Med. 2004;34(2):255-66. doi: 10.1017/S0033291703001119. [PubMed: 14982131]. 